\title{
Chemical Composition and Cytotoxicity Assessment of the Green Seaweed Caulerpa racemosa from Algerian West Coast
}

\author{
Louiza Belkacemi ${ }^{1,2}$, Tawfiq Boukhatem ${ }^{3}$ \\ ${ }^{1}$ Laboratoire de Technologie Alimentaire et de Nutrition, Site II EX-INES de Chimie, Chemin des \\ Crêtes, BP 188, Abdelhamid IbnBadis University, Mostaganem, Algeria
}

${ }^{2}$ Higher School of Agronomy of Mostaganem, Ex Hall de Technologie-Kharrouba-Mostaganem, Algeria

${ }^{3}$ Laboratoire de gestion et valorisation des ressources littorales et systématique moléculaire, Site II EX-

INES de Chimie, Chemin des Crêtes, BP 188, Abdelhamid IbnBadis University, Mostaganem, Algeria

\begin{abstract}
The objective of this study is to evaluate the chemical composition of the invasive green alga Caulerpa racemosa and to preliminary assess its possible toxicity by using the Brine shrimp lethality assay (BSLA). Caulerpa racemosa was harvested from the intertidal zone of Mostaganem coast (N 35 54'37.94", E 0³'17.37") (Algeria). Dried seaweed was either used for chemical analyzes or subjected to Soxhlet extraction using methanol, chloroform, and hexane solvents. The toxicological assessment of the extracts was carried out on Artemia salina collected from the salt lake of Bethioua (Oran, Algeria). Mortality of nauplii was evaluated after $24 \mathrm{~h}$ of exposure to the different concentrations of tested extracts. The LC50 was determined by probit regression analysis and compared to Clarkson's toxicity criteria. Caulerpa racemosa displayed a high content of total ash $(17.25 \pm 0.21 \%)$ and dietary fibers $(41.93 \pm 6.80 \%)$. Total lipid content was relatively high $(4.03 \pm 0.45 \%)$ and chlorophyll a content was greater $(20.00 \pm 0.7 \mathrm{mg} / 100 \mathrm{~g} \mathrm{DW})$ compared to the chlorophyll b. Chloroform extract exhibited the higher contents of polyphenols $(123.91 \pm 1.46 \mathrm{mg}$ gallic acid equivalent/g dry extract) and tannins $(59.28 \pm 5.43 \mathrm{mg}$ catechin equivalent/g dry extract) $(\mathrm{P}<0.001)$. The BSLA revealed the non-toxicity of all the studied extracts and the lowest LC50 was recorded for methanol extract (1047.13 ppm). Finally, the interesting chemical composition of Caulerpa racemosa and its non-toxicity suggest its possible use as a nutraceutical food. However, in vivo tests are recommended to confirm its non-toxicity and assess its nutraceutical potential.
\end{abstract}

Keywords: Brine shrimp lethality assay; Artemia salina; LC50; invasive alga; extracts. 